\title{
Pattern and Prevalence of Underweight,Overweight and Obesity Among Young Adult Nigerians
}

\author{
Oluwadare Ogunlade*, Muritala Abiola Asafa \\ Department of Physiological Sciences, Obafemi Awolowo University, Ile-Ife, Nigeria
}

Email address:

oogunlade@oauife.edu.ng (O. Ogunlade),drashafa@gmail.com (M. A. Asafa)

\section{To cite this article:}

Oluwadare Ogunlade, Muritala Abiola Asafa. Pattern and Prevalence of Underweight, Overweight and Obesity Among Young Adult Nigerians. American Journal of Biomedical and Life Sciences. Vol. 3, No. 2, 2015, pp. 12-15. doi: 10.11648/j.ajbls.20150302.11

\begin{abstract}
Body mass index (BMI) is an important cardiometabolic parameter. This study determined the mean BMI, pattern and prevalence of underweight, overweight and obesity among young adult Nigerians. It also examined the effect of sex on pattern of distribution of BMI classes. This was cross-sectional study conducted among students of a tertiary institution. Seven hundred and two (702) students (412 males and 290 females) with age range between 18-40years participated in the study. The participants had their weights and heights recorded by standardized techniques and BMI was calculated from the weight and height. BMI was classified according to WHO reference values. Data was analyzed using SPSS version 17 software. A p-value of less than 0.05 was considered as statistically significant. The mean BMI was $21.89 \pm 3.07\left(\mathrm{~kg} / \mathrm{m}^{2}\right)$. Age was positively correlated with $\operatorname{BMI}(\mathrm{r}=0.298, \mathrm{p}<0.001)$. Significant sex differences in anthropometry were demonstrated in terms of height $(\mathrm{t}=17.880$, $\mathrm{p}$ $<0.001)$, weight $(\mathrm{t}=7.595, \mathrm{p}<0.001)$, BMI $(\mathrm{t}=-2.483, \mathrm{p}=0.013)$ and BSA $(\mathrm{t}=12.716, \mathrm{p}<0.001)$. There was a significant sex difference in BMI classes recorded in this study $\left(\chi^{2}=12.255, \mathrm{p}=0.007\right)$. The prevalence of overweight and obesity among the total participants were $14.8 \%$ and $1.3 \%$ respectively. Among the males, the prevalence of underweight, overweight and obesity were $9.2 \%, 11.2 \%$ and $1.2 \%$ respectively while among the females, the prevalence of underweight, overweight and obesity were $11.0 \%, 20.0 \%$ and $1.4 \%$ respectively. More than a quarter of the apparently healthy young adults had abnormal BMI. The study also showed that abnormal BMI (underweight, overweight and obesity) were more frequent in female than male young adult Nigerians. Health education focusing on weight adjustment measures including exercise and dietary strategies will be beneficial among young adult population.
\end{abstract}

Keywords: Pattern, Prevalence, Underweight, Overweight, Obesity, Young Adult, Nigerians

\section{Introduction}

The concept of the BMI dated back to Adolphe Quetelet, who, in 1832, observed that an individual's weight is approximately proportional to the square of his/her height[1].According to World Health Organization (WHO), underweight, healthy weight, overweight and obesity were defined by BMI; $<18.5,18.5-24.9,25.0-29.9$ and $\geq 30.0 \mathrm{~kg} / \mathrm{m}^{2}$ respectively[2]. WHO also recommends BMI as the most useful population level measure of overweight and obesity, and is used as the same for both sexes and in all ages of adults [3].Overweight and obesity result from an energy surplus over time that is stored in the body as fat. How genetic and environmental factors contribute to overweight and obesity is not well understood [4]. More than 1.1 billion people in the world are estimated to be overweight and 320 million was estimated to be obese [5]. BMI is the most popular of many anthropometric indices. Indeed, it is an internationally accepted index for defining obesity [6].Overweight and obesity are defined as abnormal or excessive fat accumulation in the body that may impair health [4]. So BMI of $>25 \mathrm{~kg} / \mathrm{m}^{2}$ and $\geq 30 \mathrm{~kg} / \mathrm{m}^{2}$ are considered to be overweight and obese in adults irrespective of gender and age. This use of a single standard for obesity for all adults was recommended because it is thought to be independent of age and it can be used for making comparisons across studies [7]. BMI is a simple, safe, non-invasive and cheap way of estimating body fat percentage and assessing a person's health and nutritional status [8]. Globally, obesity has nearly doubled over the last three decades [3]. Worldwide, the proportion of adults with a body-mass index (BMI) of $25 \mathrm{~kg} / \mathrm{m}^{2}$ or greater increased between 1980 and 2013 from $28 \cdot 8 \%$ to $36 \cdot 9 \%$ in men, and from $29 \cdot 8 \%$ to $38.0 \%$ in women. Prevalence has increased substantially in children and adolescents in developed countries; $23 \cdot 8 \%$ of boys and $22 \cdot 6 \%$ of girls were overweight 
or obese in 2013[9].This upward trend is predicted to continue over coming decades [10].Global and local prevalence estimates are based on the BMI which provide a guide to obesity levels as recognized by BMI values greater than or equal to $30[11-12]$.

\section{Subjects and Methods}

\subsection{Study Population}

The participants were students of Obafemi Awolowo University, Ile-Ife, Nigeria. Seven hundred and two (702) students (412 males and 290 females) within the age range of 18 to 40years participated in the study. None of the female participants was pregnant. They were all informed about the research and consents were obtained before participating. Ethical clearance was obtained from the Ethics and Research Committee of the Obafemi Awolowo University Teaching Hospitals Complex, Ile-Ife, Nigeria.

\subsection{Anthropometry}

Measurements were taken using standardized equipment. Heights of all participants were measured using a stadiometer (OMRI Height Meter) in standing position without footwear to the nearest $0.5 \mathrm{~cm}$. Weight was measured with minimum clothes using a calibrated electronic scale with digital reading to the nearest $0.1 \mathrm{~kg}$. BMI was determined based on the formula; $\mathrm{BMI}=$ weight (in $\mathrm{kg}$ ) /height (in metres) ${ }^{2}$ and classified based on WHO cut-off values[12].

\subsection{Statistical Analysis}

Data was analysed using SPSS version 17 software. Continuous variables were presented as mean \pm standard deviation (SD). The student t-test was used to determine sex differences in the means of anthropometry.The relationship between age and BMI was determined by Pearson correlation.Sex differences in BMI classes were determined with Chi square.

\section{Results}

A total of 702 students participated in the study. Four hundred and twelve (58.7\%) were males and 290 (41.3\%) were females. The mean \pm standard deviation (SD) for ages (years), weight $(\mathrm{kg})$, height $(\mathrm{m})$, BMI $\left(\mathrm{kg} / \mathrm{m}^{2}\right)$ and body surface $\operatorname{area}\left(\mathrm{m}^{2}\right)$ for all participants were $23.55 \pm 4.48$, $61.42 \pm 9.73, \quad 1.68 \pm 0.08, \quad 21.89 \pm 3.07$ and $1.69 \pm 0.15$ respectively(Table 1). Age was positively correlated with $\operatorname{BMI}(r=0.298, p<0.001)$. All indices of anthropometry except BMI were significantly higher in men than women (Table 2). The prevalence of overweight and obesity among the total participants were $14.8 \%$ and $1.3 \%$ respectively (Table 3 ). Among the males, the prevalence of underweight, overweight and obesity were $9.2 \%, 11.2 \%$ and $1.2 \%$ respectively while among the females, the prevalence of underweight, overweight and obesity were $11.0 \%, 20.0 \%$ and $1.4 \%$ respectively(Fig.1). There was a significant sex difference in BMI classes recorded in this study $\left(\chi^{2}=12.255, \mathrm{p}=0.007\right)$.

Table 1. Demographic characteristics of all the participants.

\begin{tabular}{llll}
\hline Parameter & Mean \pm SD & Minimum & Maximum \\
\hline Age $($ years $)$ & $23.55 \pm 4.48$ & 18.00 & 40.00 \\
Weight $(\mathrm{kg})$ & $61.42 \pm 9.73$ & 37.50 & 100.00 \\
Height $(\mathrm{m})$ & $1.68 \pm 0.08$ & 1.45 & 1.93 \\
BMI $\left(\mathrm{kg} / \mathrm{m}^{2}\right)$ & $21.89 \pm 3.07$ & 16.10 & 37.10 \\
BSA $\left(\mathrm{m}^{2}\right)$ & $1.69 \pm 0.15$ & 1.29 & 2.21 \\
\hline
\end{tabular}

$\mathrm{N}=702, \mathrm{BMI}=$ Body mass index, $\mathrm{BSA}=$ Body surface area

Table 2. Sex differences in anthropometric parameters in young adults.

\begin{tabular}{llll}
\hline Anthropometry & Male $(\mathbf{n}=\mathbf{4 1 2})$ & Female(n=290) & t \\
\hline Weight $(\mathrm{kg})$ & $63.67 \pm 9.31$ & $58.22 \pm 9.43$ & 7.595 \\
Height $(\mathrm{m})$ & $1.71 \pm 0.07$ & $1.62 \pm 0.06$ & 17.880 \\
BMI $\left(\mathrm{kg} / \mathrm{m}^{2}\right)$ & $21.65 \pm 2.81$ & $22.23 \pm 3.37$ & -2.483 \\
BSA $\left(\mathrm{m}^{2}\right)$ & $1.75 \pm 0.14$ & $1.61 \pm 0.13$ & $<0.001$ \\
\hline
\end{tabular}

$\mathrm{BMI}=$ Body mass index, BSA=Body surface area

All indices of anthropometry assessed except body mass index were significantly greater in males than females.

Table 3. Prevalence of underweight, normal weight, overweight and obesity in young adults.

\begin{tabular}{llll}
\hline WHO classification of BMI $\left(\mathbf{k g} / \mathbf{m}^{\mathbf{2}}\right)$ & Frequency $(\mathbf{N}=\mathbf{7 0 2})$ & Percentage $(\%)$ & 10.0 \\
\hline Underweight & $<18.5$ & 70 & 73.9 \\
Normal weight & $18.5-24.9$ & 519 & 14.8 \\
Overweight & $25-29.9$ & 104 & 1.3 \\
Obesity & $\geq 30$ & 9 & 1.3 \\
\hline
\end{tabular}

$\mathrm{BMI}=$ Body mass index

More than a quarter of the apparently healthy young adults had abnormal BMI. 


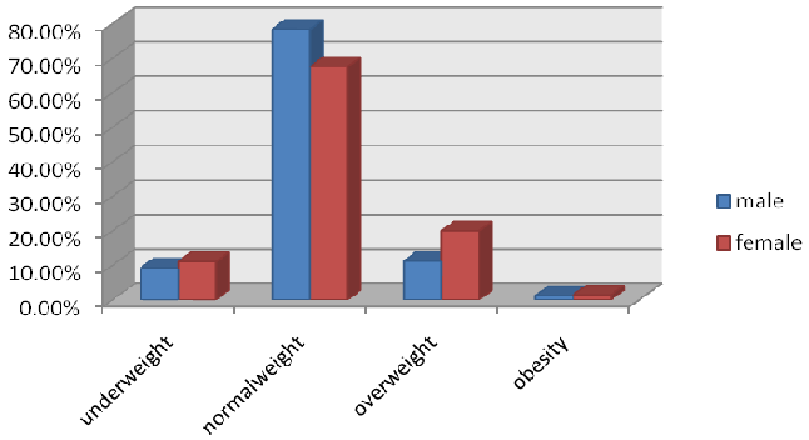

Figure 1. Effects of sex on body mass index in young adults.

Abnormal BMI (underweight, overweight and obesity) occurred more frequently in female than male young adult Nigerians. Normal or healthy weight occurred more frequently in male than female young adult Nigerians.

\section{Discussion}

The mean BMI in young adults from this study was $21.89 \pm 3.07 \mathrm{~kg} / \mathrm{m}^{2}$.Similar study carried out in Ota, Ogun State, Nigeria among young adults found the mean value for the BMI to be $22.66 \pm 0.18 \mathrm{~kg} / \mathrm{m}^{2}[13]$. The prevalence of overweight and obesity in this study were $14.8 \%$ and $1.3 \%$ respectively. These values were lower than the surveys among the general population from other parts of Nigeria with prevalence rates of overweight and obesity ranging from $21.4 \%$ to $32 \%[14-15]$.There is an alarming rate of rise in the prevalence of overweight and obesity both in developed and developing countries[16-18]. Bakariet al reported prevalence of obesity and overweight to be present in about one third of the population studied in Zaria a suburban community [14]. Adedoyin et al, 2009 conducted a survey among 2097 adult residents of Ile-Ife, a semi urban town in South-West Nigeria where they reported crude prevalence rate of $20.3 \%$ for overweight $12.5 \%$ for obesity [19].According to the health survey in England, a quarter of adults in 2013 were obese, (26 per cent of men and 24 per cent of women). Being overweight was more common than being obese and 41 per cent of men and 33 per cent of women were overweight, but not obese [20].The prevalence of normal weight was higher in male participants $(78.4 \%)$ compared to females $(67.6 \%)$ while the prevalence of abnormal BMI were higher in females than in males. These findings were consistent with data from previous studies on abnormal BMI(21-22). Amira et al, 2012 in a study of the prevalence of obesity and its relationship with hypertension in an urban Nigerian community reported a prevalence of $29.5 \%$ and $15.7 \%$ in women and men respectively. However, the study evaluated adults $\geq 18$ years in which the highest prevalence of obesity was found in the middle age group between 45-54years [21]. This notable sex difference in body mass index distribution as demonstrated in Figure1 was a pattern that had been reported in other anthropometric based studies in Nigeria population(15). The health consequences of abnormal BMI are enormous. Underweight, overweight and obesity are linked to mortality and morbidity[23].Underweight may be a pointer to starvation, anorexia nervosa or presence of debilitating chronic illness such as acquired immunodeficiency syndrome and poverty related health conditions in developing countries. Overweight and obese individuals are at increased risk numerous multisystemic health challenges involving the endocrine, metabolic, cardiovascular, respiratory, musculoskeletal and neurological systems. Diseases such as hypertension, dyslipidaemia, ischaemic heart disease, stroke, sleep apnoea syndrome, gall bladder disease, osteoarthritis, cancers and type 2 diabetes mellitus with attendant complications and increased morbidity and mortality are more frequent with people with overweight and obesity[24-25].The importance of evaluating young adult population for abnormal BMI cannot be over-emphasized. Health screening through anthropometric assessment of young population is cheap and if coupled with appropriate health education and lifestyle adjustment measures can serve as primary preventive strategy to curtail the growing trends of non-communicable diseases as the young advances in age to become the middle age population.

\section{Conclusion}

More than a quarter of the apparently healthy young adults had abnormal BMI. The study also showed that abnormal BMI (underweight, overweight and obesity) were more frequent in female than male young adult Nigerians. Health education focusing on weight adjustment measures including exercise and dietary strategies will be beneficial among young adult population.

\section{Acknowledgements}

We wish to thank the entire staff of Department of Physiology, Obafemi Awolowo University, Ile-Ife for their support.

\section{References}

[1] EknoyanG. AdolpheQuetelet (1796-1874)-the average man and indices of obesity. Nephrol Dial Transplant 2008; 23:47-51.

[2] WHO. World Health Organization (WHO) Expert Committee: Physical status: The use and interpretation of anthropometry. Report of a WHO Expert Committee, Technical reports Series $1995 ; 854$.

[3] World Health Organization: Obesity and overweight. Fact Sheet 2012;311

[4] Clinical guidelines on the identification, evaluation, and treatment of overweight and obesity in adults: The evidence report. Bethesda, Md.: National Heart, Lung and Blood Institute, 1998; NIH 98-4083.

[5] Jawad F. The obesity epidemic-a challenge of this century. Editorial, JPMA 2005.

[6] Jequier E. Energy, obesity and body weight standards. Am J ClinNutr 1987; 45:1035-1047. 
[7] Gallagher D, Visser M, Sepulveda D, Pierson RN, Harris T, Heymsfield SB. How useful is body mass index for comparison of body fatness across age, sex, and ethnic groups? Am J Epidemiol 1996; 143: 228-239.

[8] Deurenberg P, Yap M, van Staveren WA. Body mass index and percent body fat: a meta analysis among different ethnic groups. Int J Obesity 1998; 22:1164-1171.

[9] Ng M, Fleming T, Robinson M, Thomson B, Graetz N, Margono $\mathrm{C}$ et al. Global, regional, and national prevalence of overweight and obesity in children and adults during 1980-2013: a systematic analysis for the Global Burden of Disease Study 2013. Lancet.2014; 384(9945):766-781.

[10] Walls HL, Magliano DJ, Stevenson CE, Backholer K, Mannan HR, Shaw JE et al. Projected progression of the prevalence of obesity in Australia. Obesity 2012; 20:872-878.

[11] Keys A, Fidanza F, Karvonen MJ, Kimura N, Taylor HL: Indices of relative weight and obesity. J Chronic Dis 1972; 25: 329-343.

[12] World Health Organization: Obesity: Preventing and Managing the Global Epidemic. In Report of a WHO Consultation on Obesity. 1997; 894.

[13] Chinedu SN, Emiloju OC. Underweight, overweight and Obesity amongst young adults in Ota, Nigeria. J Public Health Res 2014; 6(7): 235-238.

[14] Bakari AG,Onyemelukwe GC, Sani BG, Aliyu IS, Hassan SS, Aliyu TM. Obesity, overweight and Underweight in suburban northern Nigeria. Int. J. Diabetes Metabol 2007,15:68-69.

[15] Puepet FH, Zoakah AI, Chuhwak EK (2002). Prevalence of Overweight and Obesity among Urban Nigeria Adults in Jos. Highland Med. Res. J 2006, 1(1):13-16.

[16] Cameron AJ, Welborn TA, Zimmet PZ, Dunstan DW, Owen N, Salmon J, Dalton M, Jolley D, Shaw JE. Overweight and obesity in Australia: the 1999-2000 Australian diabetes, obesity and lifestyle study (AusDiab). Medical J of Australia 2003, 178:427-432.
[17] Flegal KM, Caroll MD, Ogden CL, Curtin LR. Prevalence and trends in obesity among US adults, 1999 - 2008. JAMA 2010, 303: 235-241.

[18] Rennie KL, Jebb SA. Prevalence of obesity in Great Britain. Obes Rev 2005,6:11-12.

[19] Adedoyin RA, Mbada CE, BalogunMO,Adebayo RA, Martins $\mathrm{T}$, Ismail S. Obesity prevalence in adult residents of Ile-Ife, Nigeria. Nig Q J Hosp Med 2009, 19:63-68.

[20] Craig R, Mindell J (eds). Health Survey for England 2013, London: The Health and Social Care Information Centre, 2014.

[21] Amira C.O, Sokunbi D.O.B, Sokunbi A. The prevalence of obesity and its relationship with hypertension in an urban community: Data from world kidney day screening programme. Int J Med Biomed Res 2012;1(2):104-110.

[22] Toryila JE, Mohammed A, Adelaye AB, Achie LN, Tende JA. Prevalence of overweight and obesity among civil servants in Zaria, Nigeria. IntJor P App Scs 2009;3: 60- 65.

[23] FlegalKM,GraubardBI,Williamson DF,Gail MH. Excess deaths associated with underweight, overweight and obesity. JAMA 2005; 293(15): 1861-1867.

[24] Bhaskaran K, Douglas I, Forbes H,dos-Santos-Silva H, Leon DA, Smeeth L. Body mass index and risk of 22 specific cancers: a population-based cohort study of 5.24million UK adults. Lancet 2014;384(9945):755-765.

[25] Flegal KM, Kit BK, Orpana H, Graubard BI. Association of all-cause mortality with overweight and obesity using standard body mass index categories. A systematic review and meta-analysis. JAMA 2013; 309:71-82. 